\title{
Stereotactic radiosurgery for the treatment of melanoma and renal cell carcinoma brain metastases
}

\author{
SHELLY LWU ${ }^{1}$, PABLO GOETZ ${ }^{1}$, ERIC MONSALVES ${ }^{1}$, MANDANA ARYAEE $^{1}$, JULIUS EBINU $^{1}$, \\ NORM LAPERRIERE ${ }^{2}$, CYNTHIA MENARD $^{2}$, CAROLINE CHUNG $^{2}$, BARBARA-ANN MILLAR ${ }^{2}$, \\ ABHAYA V. KULKARNI ${ }^{3}$, MARK BERNSTEIN ${ }^{1}$ and GELAREH ZADEH ${ }^{1}$ \\ ${ }^{1}$ Division of Neurosurgery and ${ }^{2}$ Department of Radiation Oncology, University Health Network, University of Toronto; \\ ${ }^{3}$ Division of Neurosurgery, The Hospital for Sick Children, University of Toronto, Toronto, Ontario, Canada
}

Received June 20, 2012; Accepted August 17, 2012

DOI: $10.3892 /$ or.2012.2139

\begin{abstract}
Renal cell carcinoma (RCC) and melanoma brain metastases have traditionally been considered radioresistant lesions when treated with conventional radiotherapeutic modalities. Radiosurgery provides high-dose radiation to a defined target volume with steep fall off in dose at lesion margins. Recent evidence suggests that stereotactic radiosurgery (SRS) is effective in improving local control and overall survival for a number of tumor subtypes including RCC and melanoma brain metastases. The purpose of this study was to compare the response rate to SRS between RCC and melanoma patients and to identify predictors of response to SRS for these 2 specific subtypes of brain metastases. We retrospectively reviewed a prospectively maintained database of all brain metastases treated with Gamma Knife SRS at the University Health Network (Toronto, Ontario) between October 2007 and June 2010, studying RCC and melanoma patients. Demographics, treatment history and dosimetry data were collected; and MRIs were reviewed for treatment response. Log rank, Cox proportional hazard ratio and Kaplan-Meier survival analysis using SPSS were performed. A total of 103 brain metastases patients (41 RCC; 62 melanoma) were included in the study. The median age, Karnofsky performance status score and Eastern Cooperative Oncology Group performance score was 52 years (range 27-81), 90 (range 70-100) and 1 (range 0-2), respectively. Thirty-four lesions received adjuvant chemotherapy and 56 received pre-SRS whole brain radiation therapy. The median follow-up, prescription dose, Radiation Therapy Oncology Group conformity index, target volume and number of shots was 6 months (range 1-41 months), 21 Gy (range 15-25 Gy), 1.93 (range 1.04-9.76), $0.4 \mathrm{~cm}^{3}$ (range 0.005$13.36 \mathrm{~cm}^{3}$ ) and 2 (range 1-22), respectively. Smaller tumor
\end{abstract}

Correspondence to: Dr Gelareh Zadeh, Department of Neurosurgery, Toronto Western Hospital, 399 Bathurst Street, Toronto, Ontario M5T 2S8, Canada

E-mail: gelareh.zadeh@uhn.on.ca

Key words: melanoma, renal cell carcinoma, brain metastases, stereotactic radiosurgery, local control volume $(\mathrm{P}=0.007)$ and $\mathrm{RCC}$ pathology $(\mathrm{P}=0.04)$ were found to be positive predictors of response. Actuarial local control rate for RCC and melanoma combined was $89 \%$ at 6 months, $84 \%$ at 12 months, $76 \%$ at 18 months and $61 \%$ at 24 months. Local control at 12 months was 91 and $75 \%$ for RCC and melanoma, respectively. SRS is a valuable treatment option for local control of RCC and melanoma brain metastases. Smaller tumor volume and RCC pathology, predictors of response, suggest distinct differences in tumor biology and the extent of radioresponse between RCC and melanoma.

\section{Introduction}

Renal cell carcinoma (RCC) and melanoma brain metastases have traditionally been considered 'radioresistant' to conventional fractionated external beam radiotherapy and external beam whole brain radiation therapy (WBRT) (1-4). In the past decade, stereotactic radiosurgery (SRS) has become a well-established treatment modality for local control for a number of tumor subtypes $(5,6)$. The typically spherical, wellcircumscribed morphology of brain metastases provide ideal targets for SRS. One of the theoretical benefits of SRS is its potential to overcome 'radioresistance' by delivering a single fraction of high dose radiation to the hypoxic tumor core with a sharp dose fall-off in the adjacent cells (7). Given the traditional understanding that melanoma and RCC patients are resistant to radiation therapy, recent literature have focused on the role of SRS for local control of RCC and melanoma brain metastases; the limited data support a favorable response to SRS with better local control and improved survival $(8,9)$ We therefore aimed to evaluate our institutional results using SRS for treating RCC and melanoma brain metastases, with a focus on identifying predictors of response to achieve local control. We also compared the 2 tumor subtypes to determine whether there is a differential response to SRS.

\section{Materials and methods}

Ethics. This study was approved by the University Health Network Research Ethics Board of the University of Toronto. 
Patients and setting. We retrospectively reviewed a prospectively maintained database of all patients with brain metastases treated at the University of Toronto Gamma Knife (Elekta Instruments, Atlanta, GA) facility, from October 2007 to June 2010. All patients were assessed and monitored at the UHN Multidisciplinary Brain Metastasis Clinic staffed by neurosurgeons, radiation and medical oncologists. Patients were eligible to participate in the study if they had documented treatment data and clinical and radiological follow-up.

Radiosurgery treatment protocol. On the day of treatment, the Leksell frame (Elekta AB) was applied to the patient's head under local anesthesia. A high resolution gadoliniumenhanced MRI scan obtained the day prior to treatment was fused to the CT scan performed after frame placement. Using the GammaPlan (Elekta AB) software, the neurosurgeon, radiation oncologist and 2 medical physicists designed the dose plan. Doses were selected based on tumor size and location. Clinical and radiological follow-up after treatment typically occurred at 3-month intervals. Shorter follow-up intervals were performed if determined necessary by the treating physician.

Data collection. Patient demographics, treatment history and clinical follow-up information were obtained from the UHN electronic medical records. All radiological imaging was reviewed by the first author (S.L.). Treatment response was categorized as stable (no change in size or smaller) or progression. Where there were uncertainties, the MRI report was reviewed. The time to progression for intracranial disease was defined as the time between SRS and the first follow-up MRI demonstrating lesion progression. Dosimetry parameters were collected using the GammaPlan software.

Statistical analysis. Survival analysis was performed for time to progression of individual metastatic lesions. Progression-free survival estimates were determined using the Kaplan-Meier test. Exploratory univariate Cox proportional hazards regression analyses were used to identify independent variables associated with the local control. The proportional hazards assumption was confirmed by the inspection of partial residual plots as a function of time. To account for the fact that a number of patients harbored multiple lesions, the analyses were stratified based on the presence of multiple metastatic lesions. Given the limitations of the sample size, multivariate regression analysis was not performed. All analyses were performed using SPSS version 17 (SPSS, Inc., Chicago, IL).

\section{Results}

Patient population and dosimetry parameters. Of all patients treated with brain metastases at our institution between October 2007 and June 2010, 58 patients (25 RCC; 33 melanoma) were treated with Gamma Knife SRS. Thirty-six patients ( 7 females, 29 males; 16 RCC, 20 melanoma) with a total of 103 brain metastases (41 RCC, 62 melanoma) were included in the study (Table I). The median age was 52 years (range 27-81). The median Karnofsky performance status (KPS) score was 90 (range 70-100) and the median Eastern
Table I. Patient demographics.

\begin{tabular}{lc}
\hline Description & Value \\
\hline Age (years) & \\
Median & 52 \\
Range & $27-81$ \\
Gender & \\
M & 29 \\
F & 7 \\
Primary pathology (patients) & \\
RCC & 16 \\
Melanoma & 20 \\
Metastasis treated (patients) & \\
Single & 15 \\
Multiple & 21 \\
Total number of lesions & 103 \\
RCC & 41 \\
Melanoma & 62 \\
Performance Status & \\
KPS & \\
Median & 90 \\
Range & \\
ECOG & \\
Median & \\
Range & \\
Adjuvant chemotherapy & $1-41$ \\
WBRT & \\
Pre-SRS & \\
Follow-up (months) & \\
Median & \\
Range & 34 \\
\hline RCC, renal cell carcinoma; KPS, Karnofsky performance status; ECOG, \\
Eastern Cooperative Oncology Group; WBRT, whole brain radiation \\
therapy; SRS, stereotactic radiosurgery. \\
\hline$\quad$
\end{tabular}

Cooperative Oncology Group (ECOG) performance score was 1 (range 0-2). Thirty-four of the lesions received adjuvant chemotherapy and 56 received pre-SRS WBRT. The median follow-up was 6 months (range 1-41 months).

The median prescription dose was $21 \mathrm{~Gy}$ (range 15-25 Gy) (Table II). The median Radiation Therapy Oncology Group (RTOG) conformity index was 1.93 (range 1.04-9.76). The median target volume was $0.4 \mathrm{~cm}^{3}$ (range $0.005-13.36 \mathrm{~cm}^{3}$ ). The median target minimum dose was $20.16 \mathrm{~Gy}$ (range 11.62-31.85 Gy). The median number of shots were 2 (range 1-22).

Local control. Actuarial local control for RCC and melanoma combined was $89 \%$ at 6 months, $84 \%$ at 12 months, $76 \%$ at 18 months and $61 \%$ at 24 months (Fig. 1, Table III). Local control at 12 months was 91 and $75 \%$ for RCC and melanoma, respectively. 
Table II. Treatment parameters.

\begin{tabular}{lccr}
\hline Description & Mean & Median & Range \\
\hline Prescription dose (Gy) & 21.45631068 & 21 & $15-25$ \\
Conformity index (CI RTOG) & 2.5762136 & 1.93 & $1.04-9.76$ \\
CN & 0.49524272 & 0.51 & $0.1-0.93$ \\
Gradient index & 3.241262136 & 2.96 & $2.17-7.73$ \\
Target volume $\left(\mathrm{cm}^{3}\right)$ & 1.43915534 & 0.4 & $0.005-13.36$ \\
Target min dose $(\mathrm{Gy})$ & 20.2515534 & 20.16 & $11.62-31.85$ \\
Target mean dose $(\mathrm{Gy})$ & 32.29067961 & 32.47 & $20.44-51.37$ \\
No. of shots & 4.5145631 & 2 & $1-22$ \\
\hline
\end{tabular}

RTOG, Radiation Therapy Oncology Group; CI, conformity index.

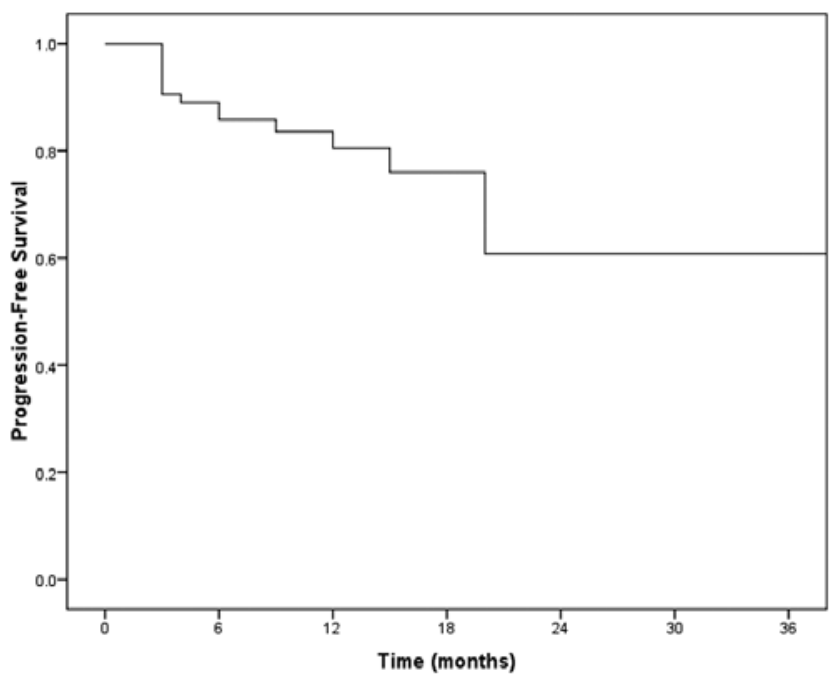

Figure 1. Kaplan-Meier survival curve

Table III. Actuarial local control (with Kaplan-Meier curve).

\begin{tabular}{ll}
\hline 6 months & $89 \%$ \\
12 months & $84 \%$ \\
18 months & $76 \%$ \\
24 months & $61 \%$ \\
\hline
\end{tabular}

Only 3 patients underwent surgical resection for treatment of local failure. Patients did not receive repeat SRS for treatment of local failure.

Predictors of response. Smaller tumor volume $(\mathrm{P}=0.007)$ and RCC pathology $(\mathrm{P}=0.04)$ were found to be positive predictors of response in univariate Cox regression analysis (Table IV). Age, ECOG score, KPS score, adjuvant chemotherapy, pre-SRS WBRT and all SRS dosimetry parameters were not found to be significant variables.

Mean tumor volume of lesions that progressed was twice the size of lesions that remained stable after SRS treatment $\left(2.62\right.$ vs. $\left.1.27 \mathrm{~cm}^{3}\right)$. Mean tumor volume of RCC metastases
Table IV. Univariate cox regression analysis.

\begin{tabular}{lll}
\hline Variable & Hazard ratio $(95 \% \mathrm{CI})$ & $\mathrm{P}$-value \\
\hline Tumor volume & $1.19(1.05-1.35)$ & $\mathrm{P}=0.007$ \\
Melanoma vs. RCC & $3.48(1.08-11.23)$ & $\mathrm{P}=0.04$ \\
Age & $1.01(0.97-1.05)$ & $\mathrm{P}=0.7$ \\
ECOG score & $1.20(0.46-3.14)$ & $\mathrm{P}=0.7$ \\
KPS score & $0.96(0.89-1.02)$ & $\mathrm{P}=0.19$ \\
Chemotherapy & $1.17(0.0 .38-3.53)$ & $\mathrm{P}=0.8$ \\
Pre-SRS WBRT & $0.98(0.30-3.26)$ & $\mathrm{P}=0.98$ \\
\hline
\end{tabular}

RCC, renal cell carcinoma; ECOG, Eastern Cooperative Oncology Group; KPS, Karnofsky performance status; WBRT, whole brain radiation therapy; SRS, stereotactic radiosurgery.

was smaller compared to that of melanoma metastases $\left(1.28\right.$ vs. $\left.1.54 \mathrm{~cm}^{3}\right)$.

\section{Discussion}

Local tumor control using SRS is a mainstay of the management for brain metastases. However, certain subtypes of brain metastases, specifically melanoma and RCC, have been considered resistant to SRS. Recent accumulating evidence supports the value of SRS for local control of melanoma and RCC, with a summary of published results presented in Table V. Our institutional experience with Gamma Knife SRS treatment of RCC and melanoma brain metastases also demonstrates that SRS is a valuable treatment option for local control for these tumor subtypes. Local control was better for RCC than for melanoma, suggesting a differential response to SRS between the 2 pathologies and a distinct difference in tumor biology. Positive predictors of response were smaller tumor volume and RCC primary pathology. Age, performance status, adjuvant chemotherapy and pre-SRS WBRT were not found to be significant variables. This highlights an important clinical decision-making point, that RCC and melanoma respond differentially to SRS.

We report 12-month local control rates of 91 and $75 \%$ for RCC and melanoma, respectively. These figures are 
TableV. Published results in the current literature concerning surivival and control in RCC/melanoma cerebral metastases.

\begin{tabular}{|c|c|c|c|c|}
\hline Authors & Cases & Local control & Survival & Local recurrence \\
\hline Brown et al (8) & $\begin{array}{l}16 \text { RCC; } \\
23 \text { melanoma - } 83 \text { lesions }\end{array}$ & $100 \%$ at 6 months & Median OS, 14.2 months & $12 \%$ \\
\hline Buchsbaum et al (1) & 74 melanoma & NR & Median, 5.5 months & NR \\
\hline Chang et al (10) & $\begin{array}{l}44 \text { melanoma, } 37 \text { renal, } 18 \text { breast, } \\
3 \text { colon, } 39 \text { non-small cell lung, } \\
5 \text { sarcoma, } 5 \text { other }\end{array}$ & $\begin{array}{l}1 \text { year, } 69 \% \text { response, } \\
2 \text { years, } 46 \% \text { response }\end{array}$ & NR & NR \\
\hline Chang et al (20) & $\begin{array}{l}103 \text { melanoma, } 77 \text { RCC, } \\
9 \text { sarcoma - } 264 \text { lesions }\end{array}$ & $\begin{array}{l}1 \text { year, } 64 \% \text { RCC; } \\
47 \% \text { melanoma; } 0 \% \text { sarcoma }\end{array}$ & $\begin{array}{l}\text { Median, } 7.5 \text { months; } \\
1 \text { year, } 40 \% \text { RCC; } \\
25 \% \text { melanoma; } 22 \% \text { sarcoma }\end{array}$ & NR \\
\hline Clarke et al (9) & $27 \mathrm{RCC}+$ melanoma & $\begin{array}{l}3 \text { months, } 82.8 \% \text { response } \\
6 \text { months, } 77.9 \% \text { response } \\
9 \text { months, } 69.3 \% \text { response } \\
12 \text { months, } 69.3 \% \text { response } \\
18 \text { months, } 55.4 \% \text { response }\end{array}$ & NR & $26 \%$ \\
\hline Gieger et al (11) & 12 melanoma, 21 lesions & $57 \%$ & NR & $43 \%$ \\
\hline Goyal et al (21) & $29 \mathrm{RCC}-66$ lesions & NR & Median, 10 months & $9 \%$ \\
\hline $\begin{array}{l}\text { Halperin and } \\
\text { Harisiadis (2) }\end{array}$ & $35 \mathrm{RCC}$ & $30 \%$ & NR & NR \\
\hline Kim et al (27) & $\begin{array}{l}26 \text { lung, } 7 \text { kidney, } 3 \text { breast, } \\
3 \text { colon - } 121 \text { lesions }\end{array}$ & 1 year, $48 \%$ & $\begin{array}{l}\text { Median, } 46 \text { weeks } \\
1 \text { year, } 39 \% \text { response } \\
6 \text { months, } 63 \% \text { response }\end{array}$ & NR \\
\hline Lavine et al (13) & 45 melanoma & $97 \%$ & Median, 43 months & NR \\
\hline Lo et al (29) & $\begin{array}{l}38 \text { melanoma }+\mathrm{RCC} \\
-66 \text { lesions }\end{array}$ & $\begin{array}{l}3 \text { months, } 87.9 \% \text { response } \\
6 \text { months, } 81.4 \% \text { response } \\
9 \text { months, } 67.9 \% \text { response } \\
12 \text { months, } 67.9 \% \text { response } \\
18 \text { months, } 60.3 \% \text { response }\end{array}$ & $\begin{array}{l}\text { Corresponding PFS, 55.3, } \\
41.9,33,23.3,13.3 \%\end{array}$ & NR \\
\hline Maor et al (3) & $46 \mathrm{RCC}$ & NR & Median, 8 weeks & NR \\
\hline Marko et al (23) & $19 \mathrm{RCC}$ & $95 \%$ & $\begin{array}{l}\text { Mean, } 21.5 \text { months; } \\
\text { Median, } 13.6 \text { months }\end{array}$ & NR \\
\hline Mori et al (14) & 60 melanoma - 118 lesions & $90 \%$ & Median, 7 months & $11.6 \%$ \\
\hline Mori et al (31) & $35 \mathrm{RCC}-52$ lesions & $90 \%$ & Median, 11 months & $10.2 \%$ \\
\hline Payne et al (24) & $21 \mathrm{RCC}-37$ lesions & $100 \%$ & NR & $0 \%$ \\
\hline Powell et al (15) & 50 melanoma, 23 RCC, 3 sarcoma & 1 year, $77.7 \%$ response & Median OS, 5.1 months & NR \\
\hline Radbill et al (16) & 51 melanoma - 188 lesions & $81 \%$ & Median OS, 26 weeks & NR \\
\hline Schoggl et al (25) & 23 RCC - 44 lesions & $96 \%$ & $\begin{array}{l}\text { Median, } 11 \text { months; } \\
1 \text { year, } 48 \%\end{array}$ & NR \\
\hline Selek et al (17) & 103 melanoma - 153 lesions & 1 year, $49 \%$ response & 1 year OS, $25.2 \%$ & NR \\
\hline Seung et al (18) & 55 Melanoma & $\begin{array}{l}6 \text { months, } 89 \% \text { response } \\
1 \text { year, } 77 \% \text { response }\end{array}$ & Median, 35 weeks & NR \\
\hline Sheehan et al (32) & 69 RCC - 146 lesions & $96 \%$ & Median, 15 months & $4 \%$ \\
\hline Shuto et al (26) & $69 \mathrm{RCC}$ & $82.6 \%$ & Median OS, 9.5 months & NR \\
\hline Wronski et al (4) & $119 \mathrm{RCC}$ & NR & $\begin{array}{l}6 \text { months, } 33.6 \% \text { response } \\
1 \text { year, } 16.8 \% \text { response } \\
2 \text { years, } 5.9 \% \text { response } \\
\text { Median, } 3.4 \text { months }\end{array}$ & NR \\
\hline Yu et al (19) & 122 melanoma - 332 lesions & NR & Median, 7 months & NR \\
\hline Kano et al (22) & 158 RCC - 531 lesions & $92 \%$ & $\begin{array}{l}\text { OS at } 6 \text { months, } 60 \% \\
12 \text { months, } 38 \% \\
24 \text { months, } 19 \% \\
\text { Median, } 8.2 \text { months }\end{array}$ & NR \\
\hline
\end{tabular}


comparable to what has been reported in the literature. Local control rates for melanoma range from 47 to $100 \%(8,10-19)$, while those for RCC range from 63 to $100 \%(8,9,15,20-26)$ (Table V). One of the challenges involved in gaining a better understanding from existing literature on this topic is that there is significant variability in how local control is defined and reported by individual groups in each study. A number of groups chose to report the actuarial local control rates at 6 or 12 months while others reported the local control rate based on the last radiological follow-up. Careful interpretation of existing literature is required and more reports of this nature adding to the body of literature with consistent criteria in assessing outcomes are necessary to gain a better understanding of specific tumor subtypes. Taking this factor into consideration, our results combined with reported data demonstrated that RCC and melanoma have a comparable local control rate when compared to other tumor subtypes, although RCC tends to demonstrate a better local control rate compared to melanoma.

The key finding of this study is that we determined that smaller tumor volume is a positive predictor of response for both RCC and melanoma to SRS. This is also supported by existing literature $(14,17,18,26-28)$. Furthermore, we discovered that the mean tumor volume of lesions that had progressed was more than double that of lesions that remained controlled. Chang et al (10) reported that one year control rates for metastatic lesions less than and greater than $1 \mathrm{~cm}$ diameter $\left(0.5 \mathrm{~cm}^{3}\right)$ were 86 and $56 \%$, respectively, using a minimum peripheral dose of $20 \mathrm{~Gy}$ for the majority of the lesions. This suggests that an aggressive approach for treating RCC and melanoma should be undertaken, with early intervention when the lesions are smaller. It also supports more frequent serial surveillance brain imaging for patients with RCC and melanoma to ensure early detection of tumor metastases at a smaller volume size. The radiobiology postulate in support of this would be a smaller total number of tumor cells with a smaller fraction of hypoxic tumor core which would therefore respond more effectively to SRS.

We identified RCC pathology to be a positive predictor of response to SRS. Lo et al (29) also discovered RCC pathology to be a positive predictor to SRS in comparison to melanoma metastasis. In our study, the mean volume of RCC metastases was smaller than that of melanoma metastases. Therefore it is possible that tumor volume was a contributing factor to RCC pathology being a positive predictor of response to SRS, and that tumor volume and tumor pathology may not be independent of each other. These data also reflect the propensity of RCC metastases to be smaller at the time of presentation to the treatment.

The small size and multiplicity of the metastases treated may have been reflective of the trend at the time at our center, which was to administer aggressive treatment of intracranial disease for radioresistant tumors in the setting of stable extracranial disease. This trend may have been in the context of obtaining control of intracranial diseases in order for patients to enroll in chemotherapy trials to treat their systemic disease. Age, performance status, adjuvant chemotherapy and pre-SRS WBRT were not prognostic factors for improved local control. Noteworthy, pre-SRS WBRT is not a prognostic factor since melanoma and RCC have typically been considered radioresis- tant. This finding questions the value of the addition of WBRT for treatment of these tumor subtypes. Due to our small event rate, we were unable to differentiate the effect of WBRT for RCC vs. melanoma. Mori et al (14) identified age $<55$ years, lack of active systemic disease and use of chemotherapy and/or immunotherapy after SRS as favorable prognostic factors in multivariate analysis. For melanoma metastases, Mathieu et al (28) revealed that predictors of local failure include increased volume of the largest irradiated lesion, increased total irradiation volume, decreased margin, maximum radiation doses and hemorrhagic metastases on univariate analysis and increased total volume of the metastases and hemorrhagic metastases on multivariate analysis. Brown et al (30) discovered that adjuvant WBRT improved local control and decreased distant brain failure with 6-month actuarial local control rates of 100 and $85 \%$, respectively, in RCC and melanoma patients. Mori et al (14) did not find the addition of WBRT to provide improved local control for melanoma. Our study supports the delay of WBRT for these tumor subtypes since pre-SRS WBRT did not provide any benefit to local control.

Limitations of the study. There are several limitations as with most retrospective studies and in particular with a challenging patient population required to maintain complete clinical and radiological follow-up. As a result of the small sample size from this single institutional experience, wide confidence intervals were obtained from univariate analysis, making it impossible to perform multivariate analysis.

Since we were mainly interested in local control, where there were multiple metastases in the same individual, each metastasis was analyzed largely independently of the other. We propose that this is a reasonable way to approach the analysis and in fact, this is really no different than what other groups have performed in the past. Although some may argue that multiple metastases in the same individual may respond to SRS similarly based on their similar genetic make-up, clinically we know this is not true. Unfortunately, literature supporting or refuting the multiclonality of multiple brain metastases is not available. Since each metastasis is not a completely independent data point, we accounted for this statistically by stratifying the Cox regression based on the presence of multiple metastases.

In conclusion, SRS is a valuable treatment option for local control of RCC and melanoma brain metastases. Predictors of response, smaller tumor volume and RCC pathology suggest distinct differences in tumor biology and the extent of radioresponse between RCC and melanoma. Concerning local control, pre-SRS WBRT did not provide an additional benefit for either RCC or melanoma subtypes.

\section{References}

1. Buchsbaum JC, Suh JH, Lee SY, Chidel MA, Greskovich JF and Barnett GH: Survival by Radiation Therapy Oncology Group recursive partitioning analysis class and treatment modality in patients with brain metastases from malignant melanoma: a retrospective study. Cancer 94: 2265-2272, 2002.

2. Halperin EC and Harisiadis L: The role of radiation therapy in the management of metastatic renal cell carcinoma. Cancer 51: 614-617, 1983.

3. Maor MH, Frias AE and Oswald MJ: Palliative radiotherapy for brain metastases in renal carcinoma. Cancer 62: 1912-1917, 1988. 
4. Wronski M, Maor MH, Davis BJ, Sawaya R and Levin VA: External radiation of brain metastases from renal carcinoma: a retrospective study of 119 patients from the M.D. Anderson Cancer Center. Int J Radiat Oncol Biol Phys 37: 753-759, 1997.

5. D'Ambrosio AL, DeYoung C and Isaacson SR: Radiosurgical management of brain metastases. Neurosurg Clin N Am 22: 45-51, 2011.

6. Kondziolka D, Flickinger JC and Lunsford LD: Radiosurgery for brain metastases. Prog Neurol Surg 25: 115-122, 2012.

7. Jagannathan J, Sherman JH, Mehta GU and Chin LS: Radiobiology of brain metastasis: applications in stereotactic radiosurgery. Neurosurg Focus 22: E4, 2007.

8. Brown PD, Brown CA, Pollock BE, Gorman DA and Foote RL Stereotactic radiosurgery for patients with 'radioresistant' brain metastases. Neurosurgery 62 (Suppl 2): S790-S801, 2008.

9. Clarke JW, Register S, McGregor JM, et al: Stereotactic radiosurgery with or without whole brain radiotherapy for patients with a single radioresistant brain metastasis. Am J Clin Oncol 33: 70-74, 2010.

10. Chang EL, Hassenbusch SJ III, Shiu AS, et al: The role of tumor size in the radiosurgical management of patients with ambiguous brain metastases. Neurosurgery 53: 272-281, 2003.

11. Gieger M, Wu JK, Ling MN, Wazer D, Tsai JS and Engler MJ: Response of intracranial melanoma metastases to stereotactic radiosurgery. Radiat Oncol Investig 5: 72-80, 1997.

12. Grob JJ, Regis J, Laurans R, et al: Radiosurgery without whole brain radiotherapy in melanoma brain metastases. Club de Cancerologie Cutanee. Eur J Cancer 34: 1187-1192, 1998.

13. Lavine SD, Petrovich Z, Cohen-Gadol AA, et al: Gamma knife radiosurgery for metastatic melanoma: an analysis of survival, outcome, and complications. Neurosurgery 44: 59-66, 1999.

14. Mori Y, Kondziolka D, Flickinger JC, Kirkwood JM, Agarwala S and Lunsford LD: Stereotactic radiosurgery for cerebral metastatic melanoma: factors affecting local disease control and survival. Int J Radiat Oncol Biol Phys 42: 581-589, 1998.

15. Powell JW, Chung CT, Shah HR, et al: Gamma Knife surgery in the management of radioresistant brain metastases in high-risk patients with melanoma, renal cell carcinoma, and sarcoma. J Neurosurg 109 (Suppl): S122-S128, 2008.

16. Radbill AE, Fiveash JF, Falkenberg ET, et al: Initial treatment of melanoma brain metastases using gamma knife radiosurgery: an evaluation of efficacy and toxicity. Cancer 101: 825-833, 2004.

17. Selek U, Chang EL, Hassenbusch SJ III, et al: Stereotactic radiosurgical treatment in 103 patients for 153 cerebral melanoma metastases. Int J Radiat Oncol Biol Phys 59: 1097-1106, 2004.

18. Seung SK, Sneed PK, McDermott MW, et al: Gamma knife radiosurgery for malignant melanoma brain metastases. Cancer J Sci Am 4: 103-109, 1998.

19. Yu C, Chen JC, Apuzzo ML, et al: Metastatic melanoma to the brain: prognostic factors after gamma knife radiosurgery. Int J Radiat Oncol Biol Phys 52: 1277-1287, 2002.
20. Chang EL, Selek U, Hassenbusch SJ III, et al: Outcome variation among 'radioresistant' brain metastases treated with stereotactic radiosurgery. Neurosurgery 56: 936-945, 2005.

21. Goyal LK, Suh JH, Reddy CA and Barnett GH: The role of whole brain radiotherapy and stereotactic radiosurgery on brain metastases from renal cell carcinoma. Int J Radiat Oncol Biol Phys 47: 1007-1012, 2000.

22. Kano H, Iyer A, Kondziolka D, Niranjan A, Flickinger JC and Lunsford LD: Outcome predictors of gamma knife radiosurgery for renal cell carcinoma metastases. Neurosurgery 69: 1232-1239, 2011.

23. Marko NF, Angelov L, Toms SA, et al: Stereotactic radiosurgery as single-modality treatment of incidentally identified renal cell carcinoma brain metastases. World Neurosurg 73: 186-193, discussion e29, 2010

24. Payne BR, Prasad D, Szeifert G, Steiner M and Steiner L: Gamma surgery for intracranial metastases from renal cell carcinoma. J Neurosurg 92: 760-765, 2000

25. Schoggl A, Kitz K, Ertl A, Dieckmann K, Saringer W and Koos WT: Gamma-knife radiosurgery for brain metastases of renal cell carcinoma: results in 23 patients. Acta Neurochir (Wien) 140: 549-555, 1998.

26. Shuto T, Inomori S, Fujino $\mathrm{H}$ and Nagano H: Gamma knife surgery for metastatic brain tumors from renal cell carcinoma. J Neurosurg 105: 555-560, 2006

27. Kim DG, Chung HT, Gwak HS, Paek SH, Jung HW and Han DH: Gamma knife radiosurgery for brain metastases: prognostic factors for survival and local control. J Neurosurg 93 (Suppl 3): S23-S29, 2000

28. Mathieu D, Kondziolka D, Cooper PB, et al: Gamma knife radiosurgery for malignant melanoma brain metastases. Clin Neurosurg 54: 241-247, 2007.

29. Lo SS, Clarke JW, Grecula JC, et al: Stereotactic radiosurgery alone for patients with 1-4 radioresistant brain metastases. Med Oncol 28 (Suppl 1): S439-S444, 2011.

30. Brown PD, Brown CA, Pollock BE, Gorman DA and Foote RL: Stereotactic radiosurgery for patients with 'radioresistant' brain metastases. Neurosurgery 51: 656-667, 2002.

31. Mori Y, Kondziolka D, Flickinger JC, Logan T and Lunsford LD: Stereotactic radiosurgery for brain metastasis from renal cell carcinoma. Cancer 83: 344-353, 1998.

32. Sheehan JP, Sun MH, Kondziolka D, Flickinger J and Lunsford LD: Radiosurgery in patients with renal cell carcinoma metastasis to the brain: long-term outcomes and prognostic factors influencing survival and local tumor control. J Neurosurg 98: 342-349, 2003 